\title{
Investigation of the parameters affecting the release of flurbiprofen from chitosan microspheres
}

\author{
Müşerref Günseli Yüksel Tilkan, Nurten Özdemir*
}

Department of Pharmaceutical Technology, Faculty of Pharmacy, Ankara University, Tandoğan, Ankara, Turkey

\begin{abstract}
Flurbiprofen (FLB), a NSAID, widely used for preventing pain generally for arthritis or dental problems. In this study, FLB loaded chitosan microspheres were prepared by ionotropic gelation method. In this method, microspheres were formed by dropping chitosan solutions containing FLB into sodium alginate solutions including sodium tripolyphosphate (TPP). A variety of formulation parameters like drug:polymer ratio, drug concentration, polymer's molecular weight, polymer concentration, $\mathrm{pH}$ and the concentration of TPP solutions, drying method and stirring time were analyzed. The dissolution studies were performed in a shaking water bath in $\mathrm{pH} 7.4$ phosphate buffer saline (PBS) at $37{ }^{\circ} \mathrm{C}$. Laser diffractometer was used for particle size analysis, and scanning electron microscope (SEM) was used for morphological properties. Drug loading and loading efficiency were calculated by using UV spectrophotometer. The particles obtained were spherical with $0.7-1.3 \mathrm{~mm}$ size range, and the loading efficiency was approximately $21-79 \%$. The dissolution studies conducted revealed that drug:polimer ratio and the polymer type and concentration affected the drug release from microspheres. It was observed that increasing the polymer concentration, polymer's molecular weight and TPP concentration decreased the FLB release from microspheres, which was according to Higuchi kinetics.
\end{abstract}

Keywords: Flurbiprofen. Chitosan. Tripolyphosphate. Ionotropic gelation. Microsphere.

\section{INTRODUCTION}

Controlled release systems have been developed against the problems commonly associated with conventional dosage forms (dosage frequency, side effects etc) (Özalp, Özdemir, 2001; Özdemir, Şahin, 1997). One of these systems, implant systems, enables targeting in local applications, as well as improving the treatment effectiveness. Implantable controlled release systems are basically polymeric implants wherein active substance release is controlled by various polymers or polymeric membranes (Danckwerts, Fassihi, 1991). Giving the active substance within a polymeric system to ensure controlled release or targeting has now been quite widespread. Polymers used in implant systems, which are capable of controlled release, are categorized into two: synthetic and natural (Wood, 1980; Davis, Hunneyball, Ratcliffe, 1985; Bogdansky, 1990; Doppalapudi et al., 2014). An attractive feature of polymers used in the preparation of

\footnotetext{
*Correspondence: N. Özdemir. Department of Pharmaceutical Technology, Faculty of Pharmacy, Ankara University, 06100 - Tandoğan, Ankara, Turkey. E-mail: nozdemir@pharmacy.ankara.edu.tr
}

implantable dosage forms is their being biocompatible and biodegradable. Although biodegradable synthetic polymers have been developed, natural polymers are widely used due to their many advantages. For example, they are not antigenic, can be metabolized, have high stability and allow for high loading for water soluble active substances (Muller et al., 1996). Chitosan, a natural biodegradable polymer, is often used in the preparation of particular dosage forms (Bodmeier, Oh, Pramar, 1989; Aral, Akbuğa, 1998; Shu, Zhu, 2002; Norkar, Sher, Pawar, 2010; Sharma et al., 2012; Al-Qadi et al., 2012, Zhang, Wang, Pan, 2014; Vivek et al., 2014; Koppolu et al., 2014; Xue et al., 2015; Chen et al., 2016; Ganguly, Kulkarni, Aminabhavi, 2016). A cationic linear bioamino polysaccharide, chitosan, is obtained by means of alkali distillation of chitin (Illum, 1998). Chitosan, composed of glucosamine and $\mathrm{N}$-acetyl glucosamine units, is a weak base. Though it is not dissolved in organic solvents, neutral and alkali pH's, it can be dissolved in diluted acids (Chandy, Sharma, 1990). Chitosan becomes positively charged when the free amino groups, which it naturally possesses, turn into a soluble state because of their protonation in acidic conditions, as a result of 
which it may react with negatively charged polymers or negatively charged surfaces such as mucosa and substrates such as fats and lipids in gastrointestinal tract that may affect lipid concentration (Bokura, Kobayashi, 2003; Hejazi, Amiji, 2003; Sumiyoshi, Kimura, 2006; Anraku et al., 2010). Chitosan is an anti-allergenic polymer which is biologically compatible with living tissues, and biodegradable. Its biodegradation products are harmless amino sugars that can be absorbed by the body (Hejazi, Amiji, 2003). Chitosan is widely used to prepare particular drug delivery systems such as microparticules (Yuan, Chessnut, Utturkar, 2007; Ma, Liu, 2010; Park, Lee, Lee, 2012; Caetano, Almeida, Gonçalves, 2016; Gadalla et al., 2016; Jeon et al., 2016).

One method used to prepare particular systems with chitosan is ionotropic gelation. This method involves development of particles by dropping the chitosan solution, prepared in acetic acid, into tripolyphosphate (TPP) or into any anionic solution at various concentrations. Microspheres form as a consequence of TPP's, a nontoxic polianion, reacting with chitosan and getting crosslinked. Then, they are filtered out, washed with distilled water, and dried (Aral, Akbuğa, 1998, Kawashima et al., 1985a; Kawashima et al., 1985b; Mi et al., 1999; Shu, Zhu, 2000; Shu, Zhu, 2001).

In this study, flurbiprofen (FLB), a nonsteroidal antiinflammatory substance, was selected as the model drug. Our purpose is preparing implantable fluriprofen containing chitosan microspheres by ionotropic gelation method for postoperative pains. We studied the effect of parameters like molecular weight and concentration of chitosan, the concentration of TPP and the drug-polymer ratio on the encapsulation efficiency, size distribution, particle morphology, release behavior of the drug and release kinetics.

\section{MATERIAL AND METHODS}

\section{Material}

Chitosans (low, medium and high molecular weight) were obtained from Aldrich, Germany. Sodium tripolyphosphate and sodium dioctyl sulphosuccinate were purchased from Sigma, Germany. Flurbiprofen was obtained from Sanovel Drug Ltd.,Turkey. Other reagents were all analytical grade.

\section{Formulation}

\section{Determination of active substance characteristics}

For the in vitro release studies, the solubility of
FLB was determined in $\mathrm{pH} 7.4$ phosphate saline buffer solution (PBS) (EP 6.0), which is used as the dissolution environment to satisfy the sink condition. For this purpose, first the stability of the active substance was confirmed in a three-month study conducted in $37^{\circ} \mathrm{C}$ PBS medium. Then, excessive amount of FLB was poured into sealed flasks including buffer solution and mixed in a $37{ }^{\circ} \mathrm{C}$ shaker water bath. The active substance content of samples filtrated out at various times was measured by UV spectrophotometry at $247 \mathrm{~nm}$. Based on the concentration values recorded when the system reached equilibrium state, the solubility of FLB was calculated $(n=3)$. The analytical method used in this study was validated for accuracy, precision, linearity, range, limit of detection and limit of quantification according to ICH Q2 (R1) (2005) (Table I).

TABLE I - Analytical validation parameters

\begin{tabular}{lcc}
\hline \multirow{2}{*}{ Parameters } & \multicolumn{2}{c}{ Results } \\
\cline { 2 - 3 } & PBS & Ethanol \\
\hline Concentration range $(\mu \mathrm{g} / \mathrm{mL})$ & 2 & 12 \\
Slope & 0,077 & 0,077 \\
Intercept & 0,012 & 0,023 \\
Determination coefficient $\left(\mathrm{R}^{2}\right)$ & 0,9997 & 0,9995 \\
SE of slope & 0,001 & 0,002 \\
SE of intercept & 0,006 & 0,006 \\
Limit of Detection $(\mathrm{LOD})(\mu \mathrm{g} / \mathrm{mL})$ & 0,389 & 1,180 \\
Limit of Quantification $(\mathrm{LOQ})(\mu \mathrm{g} / \mathrm{mL})$ & 0,456 & 1,380 \\
\hline
\end{tabular}

$S E=$ Standard error

\section{Preparation of chitosan microspheres}

Chitosan microspheres containing flurbiprofen were prepared by ionotropic gelation method (Bodmeier, Oh, Pramar, 1989). FLB was added into chitosan solutions by varying molecular weights prepared by dissolving in $1 \%(\mathrm{v} / \mathrm{v})$ acetic acid and mixed until homogenized. The chitosan solution with active substance which does not contain any air bubble was dropped into the TPP's watery solution, which is in the mean time being mixed. To improve the surface characteristics and obtain smaller particles, sodium alginate was added to the external phase (Aral, Akbuğa, 1998). The resultant particles were filtrated, which are then dried in oven at $37^{\circ} \mathrm{C}$ for 24 hours (Table II).

In this study, the effect of chitosan's molecular weight (LMw, MMw, HMw) and concentration $(1 \%, 2 \%$, $3 \% \mathrm{w} / \mathrm{v}$ ), $\mathrm{pH}$ of TPP solutions ( $\mathrm{pH} 5, \mathrm{pH} 7$ and $\mathrm{pH} 8.8$ ), 
TPP concentration ( $1 \%$ and $2 \% \mathrm{w} / \mathrm{v})$, drug concentration $(15 \%, 30 \%$ and $50 \% \mathrm{w} / \mathrm{w})$, and mixing duration $(0.5$, 1 and 2 hours) on the drug release from the particular systems prepared were investigated. The formulations are presented in Table II.

\section{Determination of the amount of drug in the microspheres prepared and incorporation efficiency}

$10 \mathrm{mg}$ of microspheres milled into powder state was mixed by the magnetic mixer in ethanol for a certain amount of time $(n=3)$. Then, the solution was filtrated, and spectrophotometric quantity determination was conducted in $247 \mathrm{~nm}$. The active substance content of the microspheres was calculated as incorporation efficiency (IE \%) by means of the equation below (Leonardi et al., 2009; Park et al., 2016).

Theoretical drug content $(\mathrm{a})=($ drug amount $/$ total solid amount) in the internal phase $\mathrm{x} 100$.

Actual drug content $(b)=$ (drug amount measured/ total solid amount used in the measurement) $\mathrm{x} 100$.
Incorporation efficiency $(\mathrm{IE} \%)=(\mathrm{b} / \mathrm{a}) \times 100$ or (actual drug content / theoretical drug content) x 100.

\section{Analysis of shape and surface morphologies of the particles}

From among the formulations prepared, the suitable ones were subject to scanned electron microscope (SEM) analysis before and after the release studies to identify their shape and surface morphologies. To this end, electron micrographical images of dry particles were taken in the SEM machine after they are gold coated (JSM - 6400, JEOL, JAPAN) (Figures 1- 4).

\section{Determination of particle size and size distribution}

Sympatec Laser Diffraction was used (Table III). Because the polymer and the active substance used is insoluble in water, measurements were made in water $(n=3)$.

TABLE II - The formulations used in the study

\begin{tabular}{|c|c|c|c|c|c|c|c|c|c|}
\hline Code & $\begin{array}{l}\text { Drug conc. } \\
(\% \mathrm{w} / \mathrm{w})\end{array}$ & $\begin{array}{c}\text { TPP conc. } \\
(\% w / v)\end{array}$ & $\begin{array}{c}\text { pH of the } \\
\text { external } \\
\text { phase }\end{array}$ & $\begin{array}{c}\text { Chitosan } \\
\text { Type }\end{array}$ & $\begin{array}{c}\text { Chitosan } \\
\text { conc } \\
(\% w / v)\end{array}$ & $\begin{array}{l}\text { Crosslinking } \\
\text { time (min) }\end{array}$ & $\begin{array}{c}\text { Tween } \\
80 \text { conc. } \\
(\% \mathrm{v} / \mathrm{v})\end{array}$ & $\begin{array}{c}\text { Sodium } \\
\text { alginate } \\
\text { conc. } \\
(\% \mathrm{w} / \mathrm{v})\end{array}$ & $\begin{array}{l}\text { Drying } \\
\text { method }\end{array}$ \\
\hline D1 & 15 & 1 & 5.0 & $\mathrm{HMw}$ & 1 & 30 & - & 0.5 & Oven, $37^{\circ} \mathrm{C}$ \\
\hline D2 & 15 & 1 & 7.0 & $\mathrm{HMw}$ & 1 & 30 & - & 0.5 & Oven, $37^{\circ} \mathrm{C}$ \\
\hline D3 & 15 & 1 & 8.8 & $\mathrm{HMw}$ & 1 & 30 & - & 0.5 & Oven, $37^{\circ} \mathrm{C}$ \\
\hline $\mathrm{F} 1$ & 15 & 1 & 5.0 & $\mathrm{HMw}$ & 1 & 30 & - & 0.5 & Oven, $37^{\circ} \mathrm{C}$ \\
\hline $\mathrm{F} 2$ & 15 & 2 & 5.0 & $\mathrm{HMw}$ & 1 & 30 & - & 0.5 & Oven, $37^{\circ} \mathrm{C}$ \\
\hline F3 & 15 & 2 & 5.0 & $\mathrm{HMw}$ & 1 & 30 & - & 0.5 & $\begin{array}{c}\text { Under } \\
\text { vacuum, } \\
\text { at } 37^{\circ} \mathrm{C}\end{array}$ \\
\hline F4 & 15 & 2 & 5.0 & $\mathrm{HMw}$ & 1 & 60 & - & 0.5 & Oven, $37^{\circ} \mathrm{C}$ \\
\hline F5 & 15 & 2 & 5.0 & $\mathrm{HMw}$ & 1 & 120 & - & 0.5 & Oven, $37^{\circ} \mathrm{C}$ \\
\hline F6 & 30 & 2 & 5.0 & $\mathrm{HMw}$ & 1 & 30 & - & 0.5 & Oven, $37^{\circ} \mathrm{C}$ \\
\hline F7 & 50 & 2 & 5.0 & $\mathrm{HMw}$ & 1 & 30 & - & 0.5 & Oven, $37^{\circ} \mathrm{C}$ \\
\hline F8 & 15 & 2 & 5.0 & $\mathrm{LMw}$ & 1 & 30 & - & 0.5 & Oven, $37^{\circ} \mathrm{C}$ \\
\hline F9 & 15 & 2 & 5.0 & $\mathrm{MMw}$ & 1 & 30 & - & 0.5 & Oven, $37^{\circ} \mathrm{C}$ \\
\hline F10 & 15 & 2 & 5.0 & $\mathrm{MMw}$ & 2 & 30 & - & 0.5 & Oven, $37^{\circ} \mathrm{C}$ \\
\hline F11 & 15 & 2 & 5.0 & $\mathrm{MMw}$ & 3 & 30 & - & 0.5 & Oven, $37^{\circ} \mathrm{C}$ \\
\hline F12 & 15 & 2 & 5.0 & $\mathrm{MMw}$ & 3 & 30 & 1 & 0.5 & Oven, $37^{\circ} \mathrm{C}$ \\
\hline F13 & 15 & 2 & 5.0 & $\mathrm{MMw}$ & 3 & 30 & 2 & 0.5 & Oven, $37^{\circ} \mathrm{C}$ \\
\hline F14 & 15 & 2 & 5.0 & $\mathrm{MMw}$ & 3 & 30 & 3 & 0.5 & Oven, $37^{\circ} \mathrm{C}$ \\
\hline
\end{tabular}



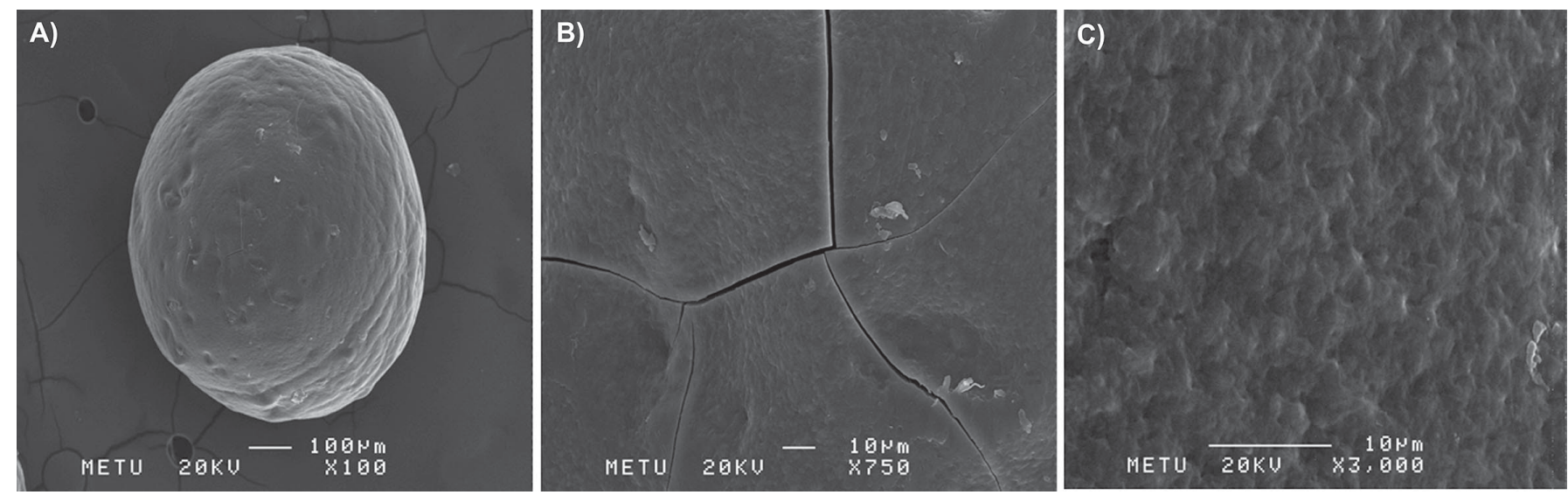

FIGURE 1 - Scanning electron micrographs of F2 coded chitosan microspheres before dissolution test: (A) general appearance and surface morphology $(\mathrm{B}, \mathrm{C})$.
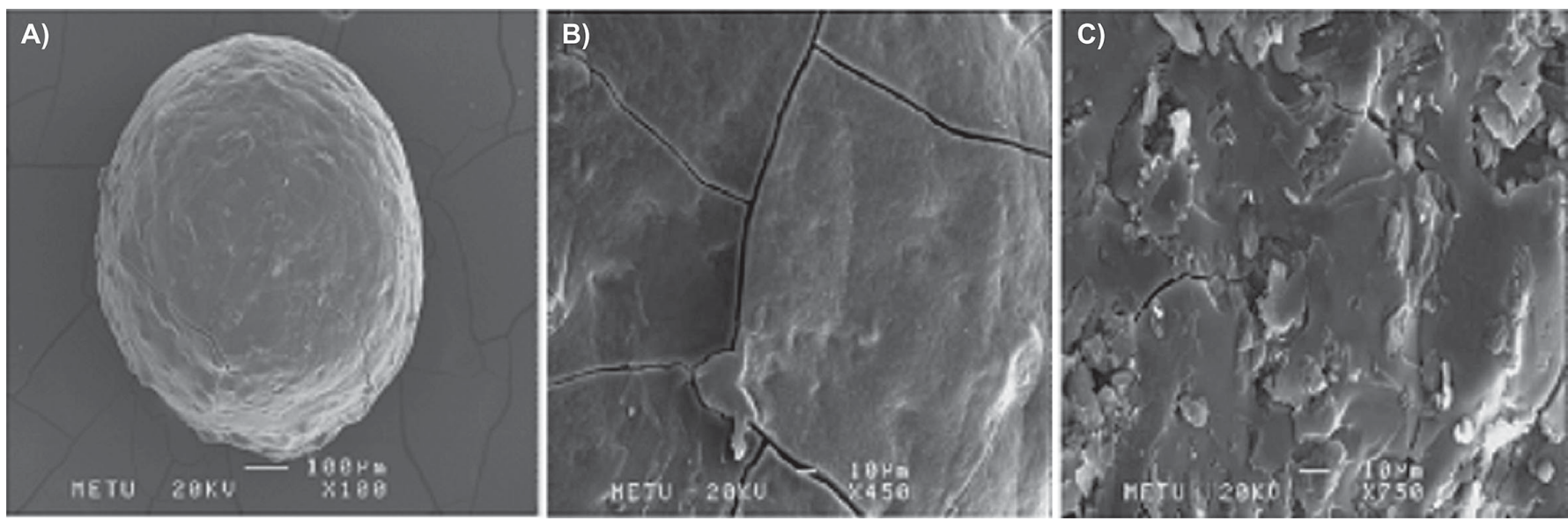

FIGURE 2 - Scanning electron micrographs of F6 coded chitosan microspheres (containing 30\%FLB)before dissolution test (A, B) and its cross sectional micrograph (C).
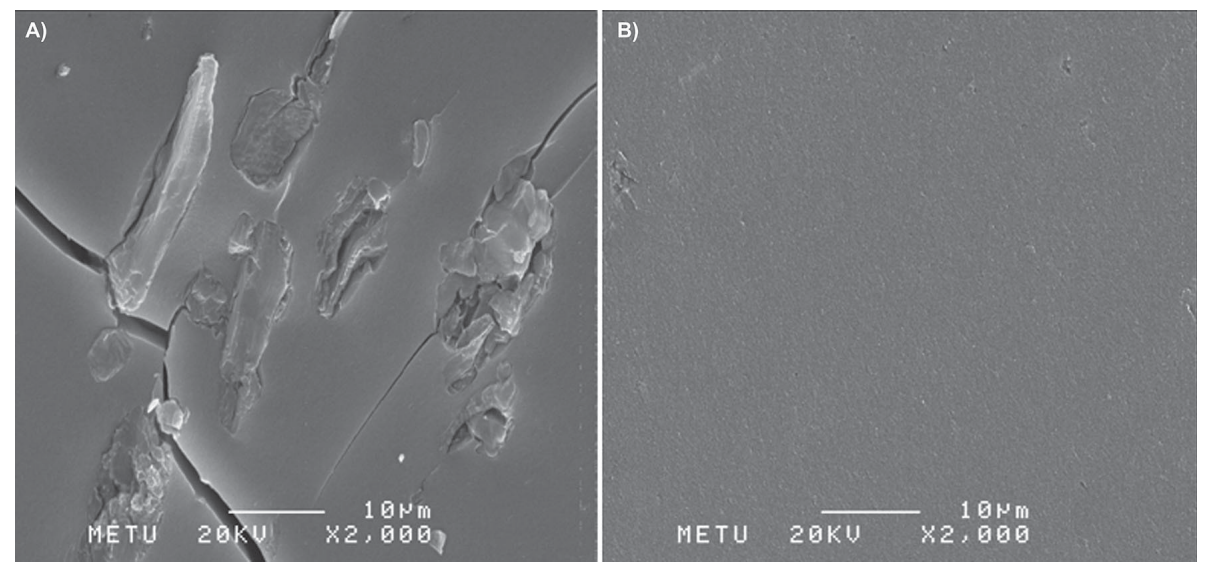

FIGURE 3 - Scanning electron micrographs of cross sections of F2 coded chitosan microspheres: (A), before dissolution test and after 24 hours from dissolution test (B).

\section{In vitro release studies}

The static method was used for the in vitro release studies under sink conditions. Particles containing approximately $10 \mathrm{mg}$ active substance were weighed, and put into $250 \mathrm{~mL}$ sealed flasks containing $100 \mathrm{~mL}$ PBS $(n=3)$. The flasks were placed into shaker water bath set to $37^{\circ} \mathrm{C}$, which can do 50 releases per minute, 

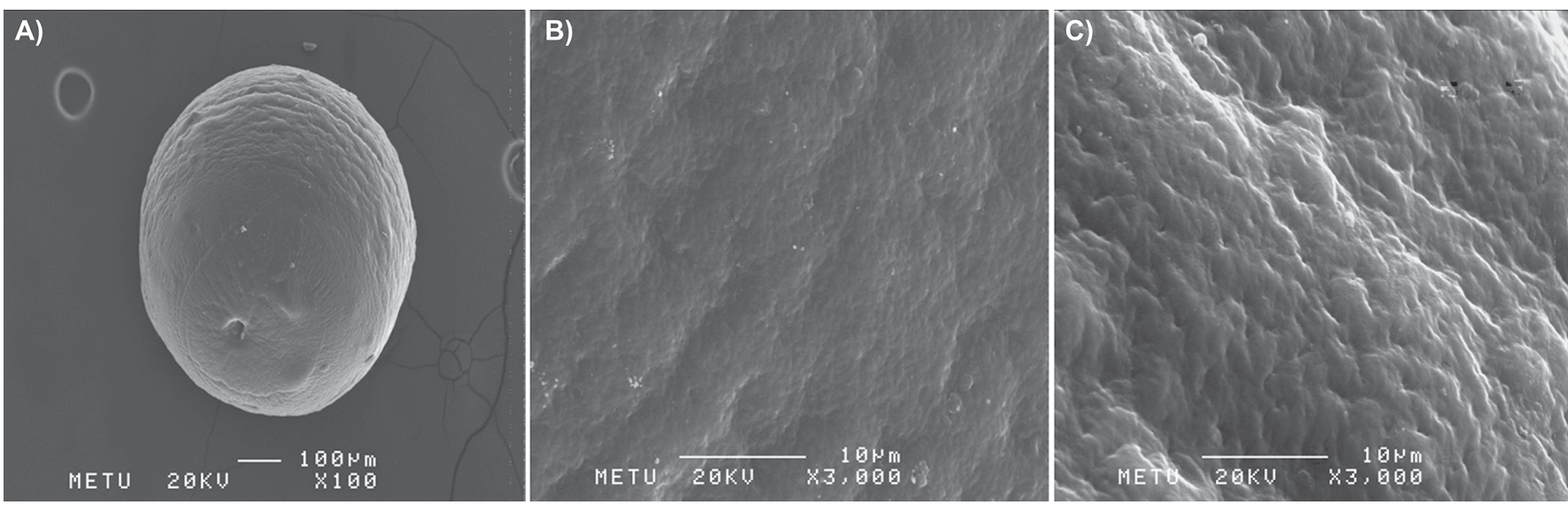

FIGURE 4 - Scanning electron micrographs of F2 coded chitosan microspheres after 24 hours in dissolution test: (A) general appearance and surface morphology $(\mathrm{B}, \mathrm{C})$.

TABLE III - Particle size analysis and incorporation efficiencies of formulations

\begin{tabular}{lccc}
\hline Formule Code & $\begin{array}{c}\text { Mean particle size } \\
(\boldsymbol{\mu} \mathbf{m} \pm \mathbf{S E})\end{array}$ & $\begin{array}{c}\text { Actual drug content } \\
(\mathbf{\%} \mathbf{w} / \mathbf{w} \pm \mathbf{S E})\end{array}$ & $\begin{array}{c}\text { Incorporation efficiency } \\
(\mathbf{\%} \pm \mathbf{S E})\end{array}$ \\
\hline F1 & $743.0 \pm 1.20$ & $5.08 \pm 0.002$ & $38.9 \pm 0.004$ \\
F2 & $702.0 \pm 1.16$ & $8.94 \pm 0.006$ & $68.5 \pm 0.026$ \\
F3 & $780.0 \pm 1.16$ & $7.11 \pm 0.003$ & $54.5 \pm 0.007$ \\
F4 & $732.0 \pm 1.14$ & $8.60 \pm 0.004$ & $65.9 \pm 0.009$ \\
F5 & $773.0 \pm 1.20$ & $7.56 \pm 0.003$ & $57.9 \pm 0.008$ \\
F6 & $713.0 \pm 1.16$ & $18.20 \pm 0.001$ & $57.9 \pm 0.001$ \\
F7 & $861.0 \pm 1.30$ & $22.09 \pm 0.001$ & $78.8 \pm 0.003$ \\
F8 & $710.1 \pm 1.32$ & $5.90 \pm 0.002$ & $45.2 \pm 0.005$ \\
F9 & $770.0 \pm 1.28$ & $6.24 \pm 0.001$ & $47.8 \pm 0.003$ \\
F10 & $759.0 \pm 1.18$ & $3.56 \pm 0.004$ & $27.3 \pm 0.009$ \\
F11 & $1086.0 \pm 1.14$ & $2.79 \pm 0.003$ & $21.4 \pm 0.006$ \\
F12 & $1069.0 \pm 1.16$ & $3.98 \pm 0.004$ & $30.5 \pm 0.010$ \\
F13 & $276.0 \pm 1.17$ & $2.79 \pm 0.003$ & $21.4 \pm 0.008$ \\
F14 & $1152.0 \pm 1.37$ & $2.65 \pm 0.003$ & $20.3 \pm 0.007$ \\
\hline
\end{tabular}

from which 1,5 $\mathrm{mL}$ samples were taken at predetermined time intervals. Then, the FLB amount released from the particles was calculated spectrophotometrically. The fresh medium was added back into the flasks in the same amount of samples taken $(n=3)$.

\section{Sterilization}

As the formulations prepared are intended to be implanted, they need to be sterilized. However, polymeric structure can be subject to change as a result of sterilization, which can affect the active substance release. Therefore, the resultant formulation was sterilized by gamma light, which is the optimum sterilization method for polymeric type drug carrying systems. Sterilization was conducted by ${ }^{60} \mathrm{Co}$ gamma ray source and Issolodovatej1 PX- $\gamma$ system with $0.51 \mathrm{Mrad} / \mathrm{sa}-\mathrm{hr}$ dose rate. Microspheres to be sterilized were placed into the radiation area, which is in the amber color glass bottles, and 2.5 Mrad was chosen as the ray dose, commonly accepted to be optimum for polymeric materials. To identify the effect of sterilization conditions on the dissolution rate, dissolution rates were measured for the formulations that were sterilized.

\section{RESULTS AND DISCUSSION}

\section{Formulation studies}

The analytical validation parameters for the UV spectrophotometric determination of FLB were given in Table I. Analyzes at a concentration range of 2-12 $\mu \mathrm{g} /$ $\mathrm{ml}$ showed that the final $\mathrm{R}^{2}$ values were close to 1 , the standard error (SE) of the slope and intercept was low, and the relative standard deviation (RSD) values were less 
than 2. Only the active substance showed peak at $247 \mathrm{~nm}$, indicating that the chosen method had selectivity for FLB.

Chitosan is a cationic polysaccharide, forming gel with negatively charged ions. Thus, TPP was used as crosslinking agent, and chitosan microspheres were prepared by ionotropic gelation method in the present study. Chitosan solution in $1 \%(\mathrm{v} / \mathrm{v})$ acetic acid was dropped onto TPP solution, which caused ionic reaction between TPP and chitosan (Hosseinzadeh et al., 2012; Joseph, Sangeetha, Gomathi, 2016), resulting in the formation of particles. In formulation studies, first, mixing rate speed and external phase $\mathrm{pH}$ were decided on. The formulations prepared are given in Table II.

\section{The effect of mixing speed}

The particles were prepared in two different stirrer (Stirpac) after a mixing process at 100, 300, 500, $1200,1500,2000$, and $5000 \mathrm{rpm}$. It was observed that microspheres do not form at such high mixing speed as $5000 \mathrm{rpm}$ and that particles tend to have a perfect spherical form as the mixing speed decreases. As a result, the optimum microsphere preparation speed was decided to be $100 \mathrm{rpm}$ (Stirpac).

\section{Determination of external phase characteristics}

External phase $\mathrm{pH}$, where TPP is located, has a direct effect on the incorporation efficiency as it will prevent transition to the external phase also because of the solubility of the active substance. In this study, the $\mathrm{pH}$ of TPP solutions was set at 5.0, 7.0, and 8.8 to prepare D1, D2 and D3 formulations, respectively. It was observed that the loading activity of $42.8 \%$ in the prepared formulation coded as D1 decreased to $16.5 \%$ in D2, and to $0.3 \%$ in D3. It was found out that, when external phase $\mathrm{pH}$ increases, encapsulation efficiency decreases because the solubility of FLB increases in the external phase (Bodmeier, Oh, Pramar, 1989; Bodmeier, Paeratakul, 1989). Therefore, external phase $\mathrm{pH}$ was kept constant at 5.0 in all studies to obstruct the passage of the active substance to the external phase and to keep it within the microspheres that developed.

\section{Volume of the external phase}

The internal phase:external phase ratios were changed to $1: 10,1: 20,1: 30$ in the formulation studies, and it was observed that the incorporation efficiency decreases, though not markedly, when the external phase volume was increased (Table III). Thus, for the ease of study, the internal:external phase ratio was decided to be $1: 10$.

\section{Crosslinking agent effect}

Chitosan solutions with varying molecular weights and concentrations were used to obtain microspheres. The study intended to use $2 \%(\mathrm{w} / \mathrm{v}) \mathrm{HMW}$, in particular, to prepare the formulations, yet microspheres could not be made due to the high viscosity of chitosan solution. It was also observed that, when $1 \%(\mathrm{v} / \mathrm{v})$ Tween 80 was added to this solution in order to decrease the viscosity and increase the flow characteristics, microspheres develop although they are deformed during the drying process. For this reason, the HMW chitosan percentage used was found out as $1 \%$.

Sodium alginate was added to the external phase along with the TPP by $0.5 \%(\mathrm{a} / \mathrm{h})$ since the existing literature has shown that this allows for particles with narrow particle size distribution and smooth surfaces (Aral, Akbuğa, 1998).

On the other hand, when microspheres were prepared by using TPP with $1 \%(\mathrm{~F} 1)$ and $2 \%(\mathrm{~F} 2)$ ratios in the external phase, it was found out that particle size decreases as TPP ratios increase (Table III) (Jain et al., 2016). Therefore, TPP concentration was set to $2 \%$ in this study.

\section{Particle size}

In this study the particle size of microspheres prepared varied between 700 and $1300 \mu \mathrm{m}$ (Table III). The effect of the formulation parameters on the particle size was analyzed.

\section{The effect of drug concentration}

In the formulations prepared by $1 \% \mathrm{HMW}$, the particle magnitude obtained were $702.05 \mu \mathrm{m}$ (F2), $713 \mu \mathrm{m}$ (F6), and $861 \mu \mathrm{m}$ (F7) when the existent active substance was $15 \%, 30 \%$, and $50 \%$, respectively (Table III). These findings are somewhat in concordance with the studies which report that cross linking density decreases, and thus particle size increases, as a result of increasing drug concentration, which leads to decreasing chitosan amount in the dribble of the same volume (Bodmeier, Paeratakul, 1989; Wan, Lim, Soh, 1994; Jain et al., 2016; Joseph, Sangeetha, Gomathi, 2016).

\section{The effect of the molecular weight of chitosan}

The existing literature has reported that porosity and particle size increase as the molecular weight of chitosan decreases because of the density of cross linking 
with TPP decreases. However, in the present study, the particle sizes were found to be $702 \mu \mathrm{m}, 770 \mu \mathrm{m}$, and 710 $\mu \mathrm{m}$ in the formulations prepared with $1 \% \mathrm{HMW}(\mathrm{F} 2), 1 \%$ MMW (F9), and 1\% LMW (F8), respectively, which is not indicative of any significant difference $(\mathrm{p}>0.05)$ (Shirashi, Imai, Otagiri, 1993).

\section{The effect of polymer concentration}

As the polymer concentration used in the prepared formulations was increased from $1 \%$ (F9) to $2 \%$ (F 10), the following particle magnitudes were achieved, respectively: $770 \mu \mathrm{m}$ and $759 \mu \mathrm{m}$. No significant difference was found between them. However, when the chitosan concentration was $3 \%(\mathrm{~F} 11)$, the particle size increased significantly to $1086 \mu \mathrm{m}(\mathrm{p}<0.05)$. These findings were attributed to the fact that TPP amount proved insufficient due to the increase in the chitosan viscosity and decrease in the cross linking density due to its being incapable of diffusing into the particles (Shirashi, Imai, Otagiri, 1993, Gan et al., 2005; Jain et al., 2016; Joseph, Sangeetha, Gomathi, 2016).

\section{The effect of crosslinking agent concentration}

It was observed that the particle size decreased when TPP concentration was increased from $1 \%(\mathrm{~F} 1)$ to $2 \%$ (F2), increasing the crosslinking density $(\mathrm{p}>0.05)$. The particle size of $743 \mu \mathrm{m}$ in F1 decreased to $702 \mu \mathrm{m}$ in F2 (Jain et al., 2016).

\section{The effect of Tween 80}

To eliminate the problems with dropping encountered during the preparation of $\mathrm{F} 12$ formulation with 3\% MMW, and the agglomeration that occurred in the microspheres that developed, Tween 80 was added to the internal phase, where lies the chitosan by $1 \%(\mathrm{~F} 12)$ and $2 \%$ (F13). The addition of Tween 80 by $1 \%$ and $2 \%$ resulted in significant reduction in the particle size. The particle size was $1086 \mu \mathrm{m}$ in the F11 formulation. It decreased to $1069 \mu \mathrm{m}$ in the existence of $1 \%$ tween 80 (F12), and to $976 \mu \mathrm{m}$ in the existence of $2 \%$ tween $80(\mathrm{~F} 13)(\mathrm{p}<0.05)$. The agglomeration problem that developed during the preparation process was also observed to have vanished.

\section{The effect of mixing duration}

This duration was fixed at 30 minutes in the formulations prepared because it was thought that the mixing duration following the crosslinking agent addition would affect the crosslinking density, and thus the particle size. IR analyses of the microspheres prepared found the existence of $\mathrm{P}=\mathrm{O}$ peaks, which indicates cross linking between chitosan and TPP. It was evidence to the sufficiency of this duration. When the duration was prolonged to 60 minutes $(\mathrm{F} 4)$ for the preparation of the formulations, no significant change occurred in terms of the particle size. This also proved that the duration of 30 minutes was sufficient for cross linking (F2). Extension of this duration into 120 minutes (F5) resulted in a significant increase in the particle sizes, which can be explained by the swelling of the microspheres during the mixing process.

\section{Morphological properties}

SEM images of chitosan microspheres are presented in Figures 1, 2, and 3. They demonstrate that the active substance is not dissolved in the matrix structure and exists in crystalized form. They also show that the shapes of the formulations are near-sphere. Figure 1 and Figure 2 indicate that, when the active substance amount was increased from $15 \%$ (F2) to $30 \%(\mathrm{~F} 6)$ in the formulations, the surface roughness increases due to the decrease in the polymer's crosslinking density. The internal structure density was also observed to have increased (Figure 2 and Figure 3). Cracks formed both on the surface and in the cross-sections of the microspheres. At the end of the 24hour dissolution rate studies, F2 coded formulations were extracted from the dissolution medium and dried. SEM analysis of these microspheres was conducted to examine the surface morphology. After the release, the analysis of the surface of the formulation showed that the polymer got loose and swollen and the pores opened. It turned out that the cracks that were observed on the surface and in the cross sections before the release disappeared after the release due to the swelling of the polymer (Figure 1, Figure 3 and Figure 4). Active substance crystals were not seen after the release (Figure 4).

\section{Release studies}

The solubility of FLB was determined in the release medium ( $\mathrm{pH} 7.4, \mathrm{PBS}$ ) was $3.77 \pm 0.11 \mathrm{mg} / \mathrm{mL}(\mathrm{n}=3)$. The effect of formulation parameters on active substance release from chitosan microspheres were analyzed with release studies under sink conditions.

\section{The effect of the molecular weight and concentration of chitosan}

High molecular weight, medium molecular weight, 
and low molecular weight chitosan was used with $1 \%(\mathrm{w} / \mathrm{v})$ ratio in F2, F8, and F9 formulations, respectively. F2 coded formulation displayed the slowest release $(p<0,05)$ (Figure $5 \mathrm{~A})$. As the molecular weight of chitosan increases, the number of amino groups that go through ionic reaction with TPP increases, which in turn boosts cross linking density. Increased number of crosslinking also increases the hardness of the structure, decreasing the active substance release (Bodmeier, Oh, Pramar, 1989; Shirashi, Imai, Otagiri, 1993; Ko, Parki Hwang, 2002; Geng, Kwon, Jang, 2005).

Figure $5 \mathrm{~B}$ shows the effect of polymer concentration on the active substance release. The F9, F10, and F11 formulations displayed on the figure contain $1 \%, 2 \%$, and 3\% MMW chitosan, respectively. As can be seen here, active substance release decreased with increased polymer concentration. Density of cross linking with TPP increases when chitosan amount increases, which leads to more intense structure formation in microspheres. This ultimately decreases active substance release $(p<0.05)$ (Ko, Park, Hwang, 2002; Berthold, Cremer, Kreuter, 1996).

\section{The effect of drug concentration}

Figure 6 presents the dissolution profiles of F2, F6, and F7 formulas prepared with $1 \% \mathrm{HMW}$ chitosan, which contain $15 \%, 30 \%$, and $50 \%$ drug concentration, respectively. When the drug amount in microspheres was increased from $15 \%$ to $30 \%$, no significant difference was observed in terms of drug release. Nevertheless, when it was increased to $50 \%$, drug release from microspheres increased significantly $(p<0.05)$. It was predicted that chitosan amount with the same droplet volume would decrease due to an increase in drug concentration, which in turn would decrease the crosslinking density. The same results were obtained for F12 and F15 prepared with 3\% MMW (Joseph, Sangeetha, Gomathi, 2016).

\section{The effect of TPP concentration and mixing duration}

F1 and F2 formulations containing 1\% and 2\% TPP, respectively, were prepared in the study (Figure 7 ). The lowest release rate was attained with the F2 formula. Cross linking was realized through the diffusion of 5 anions that exist in the TPP molecule into chitosan solutions (El-Gibaly, 2002). Therefore, the crosslinking duration is important for the strength of dribbles that develop.
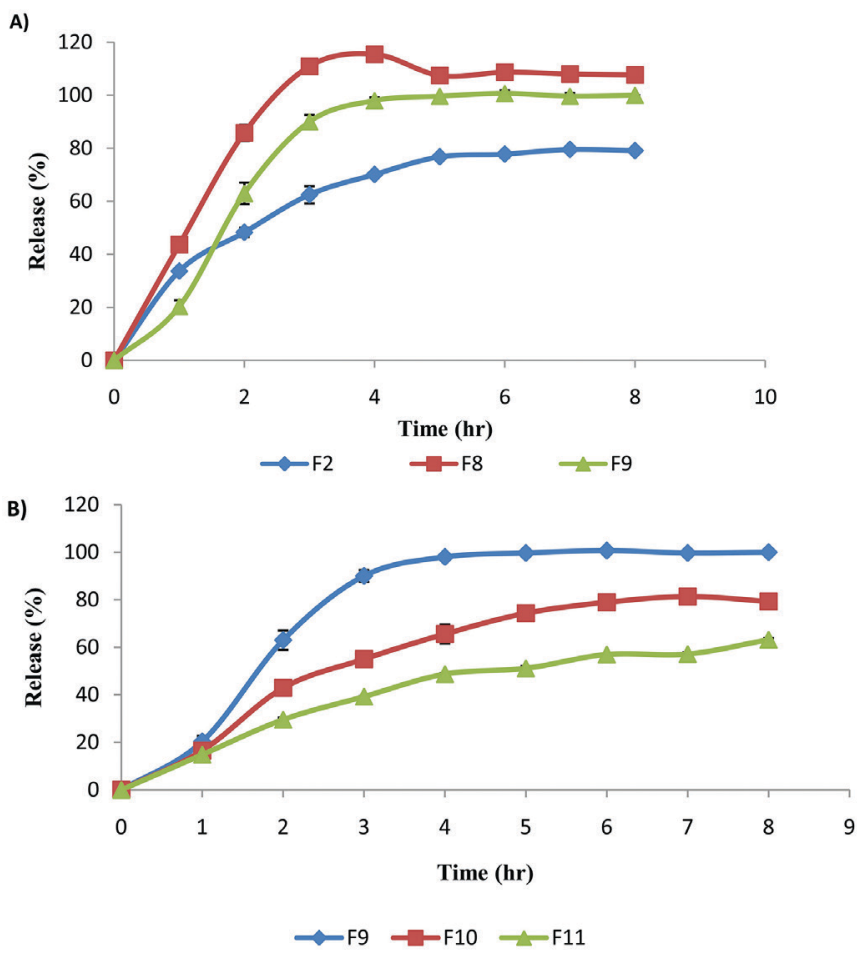

FIGURE 5 - Effect of the molecular weight and concentration of chitosan on the FLB release from chitosan microspheres in PBS: (A) F2 (1\% HMw); F8 (1\% LMw); F9 (1\% MMw); (B) F9 (1\% $\mathrm{MMw}) ; \mathrm{F} 10$ (2\% MMw) and F11 (3\% MMw).

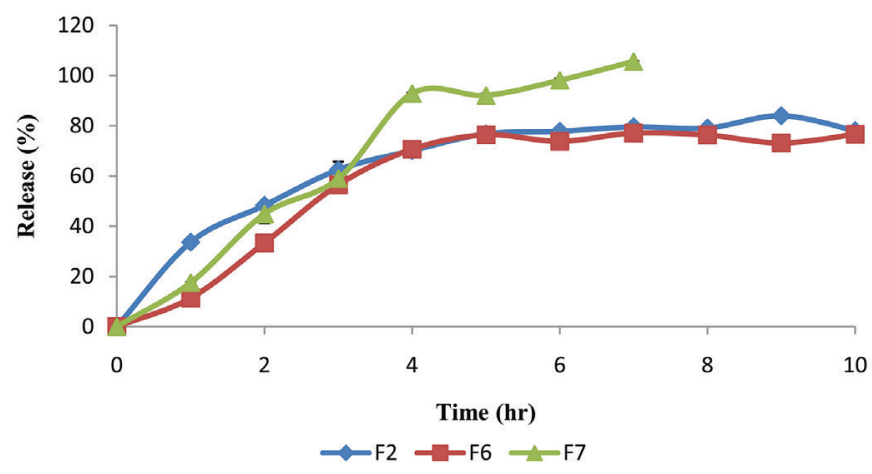

FIGURE 6 - Effect of the drug concentration on the FLB release from chitosan microspheres in PBS: F2 (15\%); F6 (30\%) and F7 (50\%).

The following formulas with varying mixing durations were prepared: F2 (30 minutes), F4 (60 minute), and F5 (120 minutes). The duration increase from 30 minutes to 60 minutes did not yield a significant difference in terms of the dissolution rate values, whereas an increase to 2 hours caused greater drug release from the formulas developed (F5) $(\mathrm{p}<0.05)$ (Figure 8). This is attributed to the fact that, although the hardening process is completed within 30 minutes, the polymer continues 


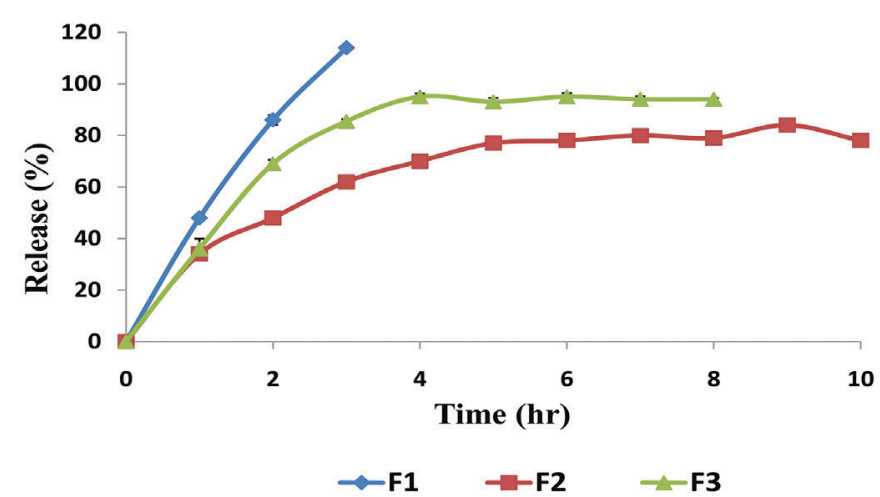

FIGURE 7 - Effect of the concentration of tripolyphosphate and drying method on the FLB release from chitosan microspheres in PBS: F1 (1\% TPP); F2 (2\% TPP); F1 and F2 were dried in the oven and F3 (2\% TPP) was dried under vacuum.

to swell, causing the drug to diffuse over the surface in the remaining time.

\section{The effect of drying conditions}

The existing studies showed that the drying conditions have a major effect on the drug release and that more surface cracks form with increased drying, which results in increased release. As can be seen in Figure 7, the drying conditions of the microspheres proved influential in substance release. The analysis of the release profiles of F2 formula dried in the oven $\left(24\right.$ hours, $\left.37^{\circ} \mathrm{C}\right)$ and $\mathrm{F} 3$ formula dried in the vacuumed oven $\left(24\right.$ hours, $\left.37^{\circ} \mathrm{C}\right)$ reveals that the active substance release in the $\mathrm{F} 2$ formula is less than that in F3 formula $(\mathrm{p}<0,05)$ (Figure 7). It was attributed to the rapid evaporation of water in vacuum during drying, and the consequent expansion of pores and quick transmission of the active substance to the surface together with water.

\section{Sterilization effect}

Dissolution rate experiment was conducted prior to and after the sterilization process to examine whether the drug release had changed or not. It was observed that sterilization process had no effect on the drug release from the $15 \%$ FLB containing F2 formulation ( $>00.05$ ). This finding led to the use of the sterilization method, which was considered suitable for microsphere formulations.

\section{Analysis of the compatibility of kinetic mechanisms}

Data obtained in the dissolution rate studies was analyzed by SPSS 11.5 in terms of compatibility

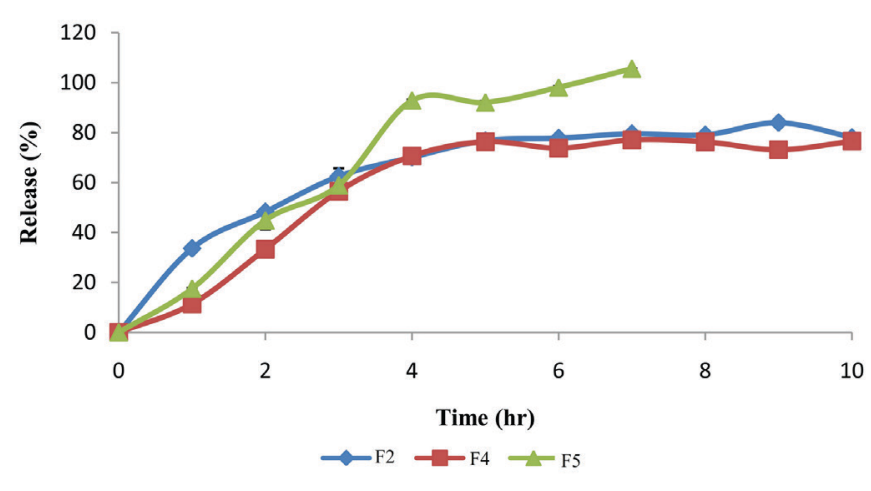

FIGURE 8 - Effect of the crosslinking time on the FLB release from chitosan microspheres in PBS: F2: $30 \mathrm{~min}$. (2\% TPP); F4: $60 \mathrm{~min}$. (2\% TPP) and F5: $120 \mathrm{~min}$. (2\% TPP).

with various kinetics (Table IV). The majority of the formulations were compatible with Higuchi $Q{ } t$ kinetics for heterogeneous matrix. It was observed that, as the chitosan's molecular weight and concentration and the TPP amount used in the formulations increased, better compatibility with $\mathrm{Q} \sqrt{ } \mathrm{t}$ kinetics was displayed. An increase in the crosslinking duration in the formulations (from 30 to 120 minutes) was associated with greater compatibility with first order kinetics, which could be explained by the swelling of the polymer resulting in the drug migration towards the surface. Being in matrix structure, the particles prepared were expected to be theoretically compatible with $\mathrm{Q} \vee \mathrm{t}$ kinetics. The releases displayed compatibility with $\mathrm{Q} \sqrt{ } \mathrm{t}$ kinetics rather than zero order, which was thought to be an indicator of the fact that dissolution rate was not solubility controlled and a matrix structure was achieved in the formulation studies.

\section{CONCLUSION}

Chitosan, which is a natural biodegradable polymer, was used in the study, and the microsphere formulas of flurbiprofen, which is not practically dissolved in water, were prepared by means of the ionotropic gelation method. It was observed that FLB's rate of release from microspheres decreased parallel to an increase in chitosan's molecular weight and concentration, and TPP concentration. SEM analysis of the microspheres revealed that they are spherical in form, with cracks on their surfaces and cross-sections. The drug release was found to be greatly compatible with the $\mathrm{Q} \sqrt{t}_{\mathrm{t}}$ kinetics. 
TABLE IV - The kinetic assesment of release data

\begin{tabular}{|c|c|c|c|c|c|c|}
\hline \multirow{2}{*}{ Formulation } & \multicolumn{2}{|c|}{ Zero Order } & \multicolumn{2}{|c|}{ First Order } & \multicolumn{2}{|c|}{$Q-\sqrt{t}$} \\
\hline & $k r^{0}$ & $r^{2}$ & $k r$ & $r^{2}$ & $k$ & $r^{2}$ \\
\hline $\mathrm{F} 1$ & 38.00 & 0.986 & 0.98 & 0.964 & 64.6 & 0.971 \\
\hline $\mathrm{F} 2$ & 0.07 & 0.516 & 0.19 & 0.916 & 28.2 & 0.953 \\
\hline F3 & 15.30 & 0.807 & 0.55 & 0.933 & 42.5 & 0.949 \\
\hline F4 & 8.41 & 0.784 & 0.18 & 0.863 & 29.6 & 0.920 \\
\hline F5 & 15.80 & 0.936 & 0.39 & 0.961 & 40.5 & 0.934 \\
\hline F6 & 11.80 & 0.875 & 0.24 & 0.917 & 34.1 & 0.917 \\
\hline F7 & 17.60 & 0.942 & 0.67 & 0.912 & 44.7 & 0.923 \\
\hline F8 & 11.10 & 0.588 & 0.98 & 0.946 & 57.5 & 0.950 \\
\hline F9 & 17.70 & 0.846 & 1.17 & 0.940 & 47.4 & 0.918 \\
\hline F10 & 11.75 & 0.916 & 0.25 & 0.989 & 34.0 & 0.966 \\
\hline F11 & 5.61 & 0.899 & 0.11 & 0.974 & 22.7 & 0.984 \\
\hline F12 & 7.29 & 0.518 & 0.08 & 0.586 & 18.3 & 0.707 \\
\hline F13 & 9.28 & 0.600 & 0.04 & 0.773 & 28.0 & 0.865 \\
\hline F14 & 6.30 & 0.567 & 0.12 & 0.681 & 23.2 & 0.827 \\
\hline
\end{tabular}

$k r^{0}=$ zero-order release rate constant; $k r=$ first-order release rate constant; $k=$ rate constant obtained from $Q$ - $\sqrt{ } t$ kinetic; $r^{2}=$ determination coefficient.

\section{REFERENCES}

Anraku M, Arahira M, Mady FM, Khaled KA, Yamasaki K, Seo $\mathrm{H}$, et al. Enhancement of dissolution and bioavailibity of flurbiprofen by low molecular weight chitosans. Pharmazie. 2010;65(7):461-467.

Al-Qadi S, Grenda A, Carrion-Recio D, Seijo B. RemunanLopez C. Microencapsulated chitosan nanoparticles for pulmonary protein delivery: in vivo evaluation of insulin-loaded formulations. J Control Rel. 2012;157(3):383-90.

Aral C, Akbuğa J. Alternative approach to the preparation of chitosan beads. Int J Pharm. 1998;168(1):9-15.

Berthold A, Cremer K, Kreuter J. Preparation and characterization of chitosan microspheres as drug carrier for prednisolone sodium phosphate as model for anti-inflammatory drugs. J Control Rel. 1996;39(1):17-25.

Bodmeier R, Oh KH, Pramar Y. Preparation and evaluation of drug-containing chitosan beads. Drug Dev Ind Pharm. 1989;15(9):1475-94.

Bodmeier R, Paeratakul O. Spherical agglomerates of water insoluble drugs. J Pharm Sci. 1989;78(11):964-67.
Bogdansky S. Natural polymers as drug delivery systems. In: Chasin M, Langer R, editors. Biodegradable polymers as drug delivery systems. New York, NY: Marcel Dekker; 1990; p. 231-259.

Bokura H, Kobayashi S. Chitosan decreases total cholesterol in women: a randomized, double-blind, placebo-controlled trial. Eur J Clin Nutr. 2003;57:721-725.

Caetano LA, Almeida AJ, Gonçalves LMD. Effect of experimental parameters on alginate/chitosan microparticles for BCG encapsulation. Mar Drugs. 2016;14(5):90-120.

Chandy T, Sharma CP. Chitosan-as a biomaterial. Biomat Artif Cells Artif Org. 1990;18(1):1-24.

Chen P, Xia C, Mei S, Wang J, Shan Z, Lin X. Intra-articular delivery of sinomenium encapsulated by chitosan microspheres and photo-crosslinked GelMA hydrogel ameliorates osteoarthritis by effectively regulating autophagy. Biomaterials. 2016;81:1-13.

Danckwets M, Fassihi A. Implantable controlled release drug delivery systems: a review. Drug Dev Ind Pharm. 1991;17(11):1465-1502. 
Davis SS, Huneyball IM, Ratcliffe JH. Recent advance in the use of microspheres for targeted therapy. Drugs Exptl Clin Res. 1985;11(9):633-640.

Doppalapudi S, Jain A, Khan W, Domb AJ. Biodegradable polymers: An overview. Polym Adv Technol. 2014;25(5):427435.

El-Gibaly I. Development and in vitro evaluation of novel floating chitosan microcapsules for oral use: comparison with non-floating chitosan microcapsules. Int J Pharm. 2002;249(12):7-21.

European Pharmacopoeia. EP 6.0. Council of Europe. 67075, Strasbourg, Cedex, France, 2008; 512 p.

Gadalla HH, Soliman GM, Mohammed FA, El-Sayed AM. Development and in vitro/in vivo evaluation of $\mathrm{Zn}$-pectinate microparticles reinforced with chitosan for the colonic delivery of progesterone. Drug Deliv. 2016;23(7):2541-2554.

Gan Q, Wang T, Cochrone C, McCarron P. Modulation of surface charge, particle size and morphological properties of chitosan-TPP nanoparticles intended for gene delivery. Colloids Surf B Biointerfaces. 2005;44(2-3):65-73.

Ganguly K, Kulkarni AR, Aminabhavi TM. In vitro cytotoxicity and in vivo efficacy of 5-fluorouracil-loaded enteric-coated PEG-crosslinked chitosan microspheres in colorectal cancer therapy in rats. Drug Deliv. 2016;23(8):2838-2851.

Geng X, Kwon O, Jang J. Electrospinning of chitosan dissolved in concentrated acetic acid solution. Biomaterials. 2005;26(27):5427-32.

Hejazi R, Amiji M. Chitosan-based gastrointestinal delivery systems. J Control Rel. 2003;89(2):151-65.

Hosseinzadeh H, Atyabi F, Dinarvand R, Ostad SN. Chitosanpluronic nanoparticles as oral delivery of anticancer gemcitabine: preparation and in vitro study. Int J Nanomed. 2012;7:18511863.

Illum, L. Chitosan and its use as a pharmaceutical excipient. Pharm Res. 1998;15(9):1326-31.

International Conference for Harmonisation. ICH. Guidelines for Industry, ICH Q2(R1). Validation of analytical procedures: methodology. Geneva. Switzerland: ICH; 2005.
Jain A, Thakur K, Sharma G, Kush P, Jain UK. Fabrication, characterization and cytotoxicity studies of ionically crosslinked docetaxel loaded chitosan nanoparticles. Carbohydr Polym. 2016;137:65-74.

Jeon SJ, Ma Z, Kang M, Galvao KN, Jeong KC. Application of chitosan microparticles for treatment of metritis and in vivo evaluation of broad spectrum antimicrobial activity in cow uteri. Biomaterials. 2016;110:71-80.

Joseph JJ, Sangeetha D, Gomathi T. Sunitinib loaded chitosan nanoparticles formulation and its evaluation. Int J Biol Macromol. 2016;82:952-958.

Kawashima Y, Handa T, Kasai A, Takenaka H, Lin SY, Ando Y. Novel method for the preparation of controlled-release theophylline granules coated with a polyelectrolyte complex of sodium polyphosphate-chitosan. J Pharm Sci. 1985a; 74(3):264268.

Kawashima Y, Lin SY, Kasai A, Handa T, Takenaka H. Preparation of a prolonged release tablet of aspirin with chitosan. Chem Pharm Bull. 1985b;33(5):2107-13.

Ko JA, Park HJ, Hwang SJ. Preparation and characterization of chitosan microparticles intended for controlled drug delivery. Int J Pharm. 2002;249(1-2):165174.

Koppolu BP, Smith SG, Ravindranathan S, Jayanthi S, Kumar S, Zaharoff DA. Controlling chitosan-based encapsulation for protein and vaccine delivery. Biomaterials. 2014;35(14):438289.

Leonardi D, Salomon CJ, Lamas MC, Olivieri AC. Development of novel formulations for Chagas' disease: Optimization of benznidazole chitosan microparticles based on artificial neural Networks. Int J Pharm. 2009;367(1-2):140-147.

Ma L, Liu C. Preparation of chitosan microspheres by ionotropic gelation under a high voltage electrostatic field for protein delivery. Colloids Surf B: Biointerfaces. 2010;75(2):448-53.

Mi F, Shyu S, Lee S, Wong T. Kinetic study of chitosantripolyphosphate complex reaction and acid-resistive properties of the chitosan-tripolyphosphate gel beads prepared by in-liquid curing method. J Polym Sci Part B: Polym Phys. 1999;37(14):1551-64.

Muller BG, Luenberger H, Kissel T. Albumin nanospheres as carriers for passive drug targeting: an optimized manufacturing technique. Pharm Res. 1996;13(1):32-37. 
Norkar M, Sher P, Pawar A. Stomach-specific controlled release gellan beads of acid-soluble drug prepared by ionotropic gelation method. AAPS PharmSciTech. 2010;11(1):267-77.

Özalp Y, Özdemir N. Controlled release of vancomycin from biodegradable microcapsules. J Microencaps. 2001;18(1):89110 .

Özdemir N, Şahin J. Design of a controlled release osmotic pump system of ibuprofen. Int J Pharm. 1997;158(1):91-97.

Park JM, Lee SY, Lee GH. Design and characterization of doxorubicin-releasing chitosan microspheres for anti-cancer chemoembolization. J Microencapsulation. 2012;29(7):695705 .

Park JW, Yun Y, Park K, Lee JY, Kim H, Kim SE. Ibuprofenloaded porous microspheres suppressed the progression of monosodium iodoacetate-induced osteoarthritis in a rat model. Colloid Surface B. 2016;147:265:273.

Sharma K, Somavarapu S, Colombani A, Govind N, Taylor K. Crosslinked chitosan nanoparticle formulations for delivery from pressurized metered dose inhalers. Eur J Pharm Biopharm. 2012;81(1):74-81.

Shirashi S, Imai T, Otagiri M. Controlled release of indomethacin by chitosan-polyelectrolyte complex: optimization and in vivo/ in vitro evaluation. J Control Rel. 1993;25(3):217-25.

Shu, XZ, Zhu KJ. A novel approach to prepare tripolyphosphate/ chitosan complex beads for controlled release drug delivery. Int J Pharm. 2000;201(1):51-58.

Shu XZ, Zhu KJ. Novel pH-sensitive citrate cross-linked chitosan film for drug controlled release. Int J Pharm. 2001;212(1):19-28.
Shu XZ, Zhu KJ. Controlled drug release properties of ionically crosslinked chitosan beads:the influence of anion structure. Int J Pharm. 2002;233(1-2):217-25.

Sumiyoshi M, Kimura Y. Low molecular weight chitosan inhibits obesity induced by feeding a high-fat diet long-term in mice. J Pharm Pharmacol. 2006;58(2):201-207.

Vivek R, Thangam R, Nipunbabu V, Ponraj T, Kannan S. Oxaliplatin chitosan noparticles induced intrinsic apoptotic signaling pathway: a "smart" drug delivery system to breast cancer cell therapy. Int J Biol Macromol. 2014;65:289-97.

Wan LSC, Lim LY, Soh BL. Drug release from chitosan beads. STP Pharma Sci. 1994;4(3):195-200.

Wood DA. Biodegradable drug delivery systems. Int J Pharm. 1980;7(1):1-18.

Xue M, Hu S, Lu Y, Zhang Y, Jiang X, An S, et al. Development of chitosan nanoparticles as drug delivery system for a prototype capsid inhibitor. Int J Pharm. 2015;495(2):771-782.

Yuan Y, Chessnut BM, Utturkar G. The effect of cross-linking of chitosan microspheres with genipin on protein release. Carbohyd Polym. 2007;68(3):561-67.

Zhang J, Wang D, Pan J. Efficient resveratrol production by immobilized $\beta$-glucosidase oncross-linked chitosan microsphere modified by 1-lysine. J Mol Catal B: Enzym. 2014;104:29-34.

Received for publication on $19^{\text {th }}$ December 2016 Accepted for publication on $17^{\text {th }}$ April 2017 